\title{
Performing the Self in the Mainstream
}

\author{
Norwegian girls in blogging
}

\author{
Karolina Dmitrow-Devold
}

\begin{abstract}
Blogging has become an integral part of girls' media culture in Norway. This article investigates how teenage girls in the mainstream blogging community perform selves in their blogs over time. While studies of girls' self-presentations online abound, most draw solely on analyses of online artefacts and lack a temporal perspective. To address these gaps, this investigation has employed a longitudinal design combining in-depth interviews with ethnographic content analyses of blogs, and has analysed girls' online-based performances of self as integral to their offline experiences framed by the wider cultural context and gendered discourses. This approach is fruitful because it acknowledges girls' changing experiences across time and contexts, thus making possible a contribution to the theorization of identity as performed across the online and the offline settings and interactions in an ongoing process.
\end{abstract}

Keywords: girl culture, identity, online/offline

\section{Introduction}

Blogging has become an integral part of Norwegian girls' media culture (Fuglerud 2013), despite its rather limited diffusion among the Norwegian population as a whole. 53 per cent of Norwegian girls aged 15-16 visit, author or comment on blogs (Norwegian Media Authority 2016) and some blogs authored by young women have massive audiences. Top bloggers are celebrities, framed as role models for girls. Rysst \& Roos (2014) have observed that top blogs are a source of the body-image pressure experienced by Norwegian girls. Research on blogging is thus important in order to gain some insight into girls' experiences of participation in the current mainstream media culture.

This article brings the literature on self-presentation online into conversation with the literature on girls' and young women's femininity and sexuality online by addressing the following research question:

How do girls who blog in the mainstream blogging community in Norway perform blogging selves over time?

Dmitrow-Devold, Karolina (2017) Performing the Self in the Mainstream. Norwegian girls in blogging in Nordicom Review 38 (2017) 2, pp. 65-78. doi:10.1515/nor-2016-0391 
This investigation is longitudinal and emphasizes girls' perspectives on participation in mainstream blogging, which allows insight to their experiences of performing blogging selves over time rarely addressed the literature. The goal is to acknowledge, document and theorize girls' experiences and changing perspectives.

I define mainstream blogging in Norway as encompassing both the blogg.no community, which is the largest, and the blogging genre viewed as most typical for young female bloggers (Fuglerud 2013): personal blogs including life updates and so-called outfit photos. ${ }^{1}$ This investigation does not cover other blogging communities and genres, such as fitness or fashion blogs.

\section{Nordic girlhood}

Nordic countries rank favourably in international gender-equality statistics. This relates to "several decades of women's movement activism and welfare state intervention, targeting women's participation in the public sphere of employment and politics and change in the traditional, gendered division of domestic work" (Sümer et al. 2014). Like their Anglo-American peers, Norwegian girls are subject to body-image pressure (Jávo 2012, cited in Rysst \& Roos 2014), eating disorders, and body-hatred resulting from the increasing focus on the body characteristic of neoliberal postfeminist sensibility (Rysst 2010). Nordic Girlhood is unique because it leans on discourses that emphasize "innate likeness of girls and boys" and gender integration and frame gender differences as resulting from socialization (Formark \& Bränström Öhman 2013: 4). This produces a normative ideal of a strong, independent girl who can and should do whatever she wants and downplays the potential hindrances due to structural dimensions of gender (ibid.). Norwegian girls today, especially from the middle class, ${ }^{2}$ must be "perfect at everything: look great, have a slim and toned body, an exciting social life, and be very good at school" (Nielsen 2014: 87, my translation). Being feminine and clever are no longer assumed to be contradictory, something Nielsen (2014) views as both liberating and challenging.

\section{Mainstream blogging as part of girls' media culture}

Though I document Norwegian girls' performances of selves in the online-based mainstream blogging community, I have striven to analyse these performances as integral to their offline experiences framed by the wider cultural context and gendered discourses. I view mainstream blogging as illustrative of the postfeminist sensibility (Gill 2007) in that femininity norms promoted by top female bloggers focus on consumerism, the technology-enabled body (Jackson 2016), and hetero-normative sexuality that seems to originate in what Abidin \& Thompson (2012) call "refracted (fe)male gaze", whereby women "monitor and discipline each others' bodies on the basis of presumed heterosexual masculine desires" (468). This article does not investigate top blogs, ${ }^{3}$ but I have earlier identified (Dmitrow-Devold forthcoming) that top bloggers are trendsetters of femininity norms in mainstream blogging and thus frame the self-presentations of the girls in this study.

I position mainstream blogging as illustrative of three recent trends in youths' digital media culture: the competition for positive responses within the judgement culture 
(Hirdman 2007), because girls continually perform selves online and the audience judges these performances; celebrity culture (boyd 2008), because high-ranking female bloggers become celebrities; and increasing commercialization of children's and teen's media culture (Schor 2004), because some bloggers receive products or money from advertising.

Moreover, I conceptualize the term "pink blogger" as an identity label (Moje \& Luke 2009), which represents a gendered discourse that positions girls' participation in mainstream blogging in mostly negative ways. On the basis of my critical discourse analysis of Norwegian press articles (Dmitrow-Devold 2013), I argue that this label reflects the disparagement of feminized media genres that media studies (Gray 1992, Herring et al. 2004) have documented: it positions mainstream female bloggers as homogenously superficial. "Pink bloggers" originally denoted teenage girls who blog about personal life and style. They were positioned as unworthy of public attention and wasting their voices on trivialities. Historically, women's public visibility in Norway has been largely connected to the second-wave feminist movements that initiated and pushed forward the fight for social gender equality. In this light, an engagement in the public sphere based on the accounts of teenage life and style seems misguided and incompatible with the normative ideal of Nordic Girlhood (Formark \& Bränström Öhman 2013). At present, the "pink blogger" label is mostly associated with top female bloggers in their twenties who blog for a living and conveys additional connotations of the commodification of personal communication and of promoting unrealistic body ideals. The changing connotations mirror the gradual shift in mainstream blogging towards professionalization and commercialization, including the problematic aspects.

\section{Studies of self and femininity online}

People tend to portray themselves online according to the same categories that exist offline, such as gender or race (e.g., Nakamura 2002, Robinson 2007), rather than constructing alternative identities unconstrained by one's life or body (e.g., Turkle 1995). Still, we can filter ourselves online (Rettberg 2014), either literally, by using photo filters or Photoshop, or culturally, by hiding aspects of self which diverge from community norms and from what we want to show the anticipated audience. The performance of self also depends on the degree of anonymity in a particular online setting, its purpose and structure (Marwick 2014), and its norms of behaviour - hence a variety of girls' self-presentations documented previously (Sveningsson Elm 2007).

Today, girls' performances online are contextualized by postfeminist popular culture, which frames bold hetero-normative sexuality and the focus on the technology-enabled body (Jackson 2016) as individual empowerment (McRobbie 2009, Gill 2007). Stern (2004) proposes that online spaces enable adolescents to experiment with self-presentation styles more freely than offline spaces, where social constraints are stronger. Some scholars (Kelly et al. 2006, Daneback 2006, Willem et al. 2012) point to showing more skin, adopting traditionally masculine sexual scripts or playing with conventional codes of gender display as instances of such experimentation. Still, normative femininity requires girls to balance physical attractiveness with respectability (Ambjörnsson 2004). While young women transgress the traditional gender roles by, say, posting sexualized photos and acting raunchily online, they tend to balance these transgressions by emphasizing self-worth and autonomy (Dobson 2012). 
Some studies of Nordic girls' self-presentations online show similar balancing acts. Sveningsson Elm (2009) finds that the girls who posted revealing photos in the Swedish online community also emphasized their involvement in romantic relationships, which she interprets as the balancing between "the undesired polarities of the attractive but too available 'whore', on the one hand, and the unattractive, unwomanly woman, on the other" (97). Such dilemmas are also present on websites that explicitly encourage publishing sexualized photos, like the site deiligst.no (Helseth 2010), where girls (and boys) post photos of their bodies and compete for the audience's highest score for "hotness". Studies of these kinds of websites in Norway and Sweden (Knudsen 2007, Hirdman 2007) show that the girls' photos are sexualized, often evoking soft-pornographic aesthetics. Helseth (2010) rightly argues that competing for the audiences' scores by exposing one's body is not an expression of girls' free play with sexuality because they risk, much more than boys, being labelled as slutty or desperate if they fail to exhibit sexual availability to men in just the right way. An investigation of girls' profiles on a Danish teen portal demonstrates that positive comments from peers are the biggest motivators for girls to post sexualized photos, because they bring popularity in this competitive setting (Gram \& Richardt 2006).

These sites engage with celebrity- (boyd 2008) and judgment culture (Hirdman 2007) that originate in docu-soaps and reality-TV, where the participants compete with each other for the audience's highest score. Lövheim's (2011) investigation of top blogs authored by Swedish women also highlights a competitive online community, where bloggers use various techniques to enlarge their audiences, which lead to high positions on blog rankings and therewith popularity and material benefits. The blogging community investigated here is also competitive and engages with celebrity culture in that it frames girls as competitors for the highest positions in the blog rankings and the most popular bloggers gain celebrity status within and outside of this community. However, while Lövheim (2011) focuses on top bloggers in their twenties who blog for a living, I have focused on teenage girls who blog in their spare time and have smaller audiences.

While numerous studies focus specifically on girls' self-presentations online (e.g., Sveningsson Elm 2009, Dobson 2012), most of them draw solely on the analyses of the online artefacts the girls produce and mostly lack a temporal perspective (see, however, Gram \& Richardt 2006, Davis 2010). Consequently, we seldom learn about the girls' experiences of self-presentation or how they self-present over time.

\section{Theoretical framework - the blogging self as relational and situated}

This study employs the concept of performing the blogging self, drawing on Lomborg's blogging self (2012) and Goffman's performed self (1959). These symbolic interactonist concepts presume that in any social interaction "some elements of our identity are highlighted, while others are toned down" (Lomborg 2012: 416). A blogging self is not fixed but is relational, situated in the interactions with the context - the blogging community - and the audience. The girls perform this character (Goffman 1959) for their audiences. While the concept of the blogging self allows for investigating girls' performances of self situated in everyday interactions with the blogging community and the audience, I conceptualize these performances as an integral part of the girls' offline experiences framed by the wider cultural context and gendered discourses, including 
the "pink blogger" label. Identity is performed in an ongoing process across the online and the offline settings (Thurlow et al. 2004).

I draw on postructuralist (Butler 1990) and relational (West \& Zimmerman 1987, West \& Fenstermaker 1995, Fenstermaker \& West 2002) approaches to gender, rather than on Goffmanian (1976) gender display. I view girls' blogging selves as both discursively performative, drawing on the multiple, fluid femininities emphasized by poststructuralism, and as situated in everyday social interactions constrained by gender structures that hold girls accountable for their performances of femininity. I also presume that different femininities are valued differently, with normative femininity requiring the balancing of physical attractiveness and respectability (Ambjörnsson 2004).

\section{Method: Investigating blogging self across time and contexts}

This study is a part of a larger project that combines ethnographic methods with discursive analyses of media commentary about mainstream female bloggers, rather than an ethnography per se. The methods reflect the focus on girls' perspectives and the theorization of the blogging self as situated and framed by both the online-based and the offline-based experiences and contexts. In line with this study's theoretical view of the online and offline settings as intertwined in the ongoing process of performing the self, I collected data from both online (participants' blogs) and offline sources (press articles, interviews with participants). The analyses of these different sources of data fed into each other.

The longitudinal design tracked the girls' performances of selves and their experiences over time. The data-collection stages were: 1) interview one; 2) archiving blog posts and readers' comments; 3 ) interview two carried out six months after interview one $^{4}$. It is important to note that the data collection and the analyses intertwined. I analysed the data collected at each stage before embarking on the next. The stories I heard during the interviews contextualized the content I found in the blogs and vice versa: the interviews made it possible for me to ask about the performances of self I had identified in the blogs. This presence of the participants (see also Duguay 2016) supported my investigating their experiences. Interviewing the participants twice, analysing their blogs between the interviews and encouraging them to reflect on their past and present performances formed a critical part of the longitudinal analyses.

To capture how the girls not only performed blogging selves but also how they experienced and justified these performances, I combined interviews with ethnographic content analyses (Altheide 1996) of their blogs. Semi-structured interviews were conducted face-to-face ${ }^{5}$ during 2012-2014, audio recorded, and transcribed. Using mostly open-ended questions, I elicited the girls' stories of participation in mainstream blogging over time. Departing from these stories, I asked about experiences, dilemmas, and goals tied to the performances of self. Drawing on my earlier analyses of Norwegian press articles (Dmitrow-Devold 2013), I also analysed how the participants positioned themselves in relation to the "pink blogger" label, an iteration of a gendered discourse that frames participation in mainstream blogging. Drawing on the social constructionist framework, I investigated both what the participants said and how they said it (Silverman 2006): I viewed them not simply as individuals with their unique experiences but rather as members of a culture who "use culturally available resources in order to con- 
struct their stories" (134). I applied ethnographic content analysis (Altheide 1996) for the investigation of the performances of self in the blog samples focusing on the topics, photos and videos, and the readers' comments.

The purpose of this investigation is to contribute to the theoretical development of the performing identity as self (Moje \& Luke 2009) in online-based settings, rather than to provide a generalizable description of teenage female bloggers in Norway. Purposive sampling (Lincoln \& Guba 1985) was used to select a strategic sample conducive for understanding and developing concepts that would provide explanations of the investigated phenomena. The size of the strategic sample was determined on the basis of theoretical saturation. The sample included 12 participants of the mainstream blogging community, as defined above: girls aged 15-17 whose blogs were part of the blogg.no community and included life accounts as well as outfit photos. For the sake of securing the longitudinal collection of blog samples, ${ }^{6}$ I only included participants who had blogged at least six months prior to recruitment. The participants had various audience sizes. ${ }^{7}$

\section{Results: Three strategies of performing the blogging self}

The analyses led me to identifying three strategies of performing the blogging self. I called these strategies because the girls emphasized and filtered out aspects of the blogging self according to changing goals. At the same time, the judging audiences (Hirdman 2007), the competitiveness, and the norms of polished femininity promoted by celebrity bloggers framed their performances. The strategies mirror the different ways the participants tried to respond to these norms: adjusting to the norms in the adjustment strategy; both adjusting to the norms and presenting potentially deviating aspects of self in the fit-in-and-be-myself strategy; and contesting these norms in the contestation strategy.

These strategies are refined, analytical products derived from the empirical material. Some girls reflected them to varying degrees. Some used different strategies over time. Instead of relating the stories of all participants, I present the essential characteristics of each strategy and provide illustrative examples. Subsequently, I present the dynamics of performances of blogging self across time and contexts focusing on several participants. While this format reduces the thickness of the presented analyses, it makes for a clear understanding of the concepts that provide explanations of the investigated phenomena.

\section{Adjustment strategy}

The typical elements of this strategy comprise: focusing on style-related topics in favour of opinionated, negative or private content; constructing a positive image of oneself; distancing oneself from one's blogging self. The below quotation illustrates this strategy:

[T]o blog about superficial things is quite external to me in a way. The blog is not me; it's just a small part of what I am interested in. I'm more likely to get through to readers with something that a lot of them can relate to - clothes and shoes and such - rather than just writing about me and my life. Sara, interview.

The posts typically include short updates on the day and carefully staged outfit photos. The photos are numerous and dominate the posts but they neither expose bodies in sexualized poses nor document undergone beauty treatments and/or plastic surgery, 
which the participants associate with top bloggers. Rather than transgressing the norm of respectability (Ambjörnsson 2004), they carefully avoid posting "provocative" photos. For instance, while bikinis appear in the "new in" section, displayed on a table, they are rarely presented on the person.

In this strategy, the girls say they look "more perfect" than "in reality". Whereas choosing the most flattering online profile photos has been documented as common (Kapidzic \& Herring 2014), here the selection is very restrictive. Lisa said she only feels comfortable looking "dolled up" in the blog and the photos confirm this: she always has full, immaculate make-up. Ella takes up to 100 photos for one post, only to choose a few which she subsequently edits to enhance them. Another element is emphasizing positive aspects of personality and projecting a positive attitude to life, because this is "more fun for the readers". By filtering out (Rettberg 2014) critical worldview and negative emotions that could "offend" someone, the girls construct blogging selves that are easy to consume, which is typical for micro-celebrities (Marwick \& boyd 2011): people who become popular online. Indeed, in my sample, switching to this strategy tended to give an increase in audience size. This indicates that the polished and positive performances of self can lead to large audiences.

The girls frame their polished blogging selves as responses to both the overwhelming focus in society on the perfect body, where "you have to be thin but also have muscles... be pretty, have long hair, nice clothes and bags" and the judging audience's reactions, where "a normal person gets comments that she is super fat or super skinny". "Society has gone crazy", said Lisa. In this strategy the girls respond to this "craziness" by trying to adjust their blogging selves to the premises laid out by the blogging community's trendsetters and the postfeminist culture, where looking good, wearing the right clothes, and having a slim, toned body are essential.

Though audiences often compliment these "perfect" self-presentations - "I'm totally jealous of your hair, it's soooo great!"; "You are dead gorgeous!:)" - the girls seemingly never manage to be "perfect" enough. Sara received critical comments for wearing "too short" dresses, Lisa for posting about parties with alcohol, and Nora for being "too thin". The readers seemed to discipline the bloggers according to the refracted (fe)male gaze (Abidin \& Thompson 2012), denouncing the show of too much skin as a signal of intolerable sexual availability or the failure to comply with the rigid ideal of the body that is neither too fat nor too thin (Rysst 2010).

Interestingly, the girls who used the adjustment strategy typically distanced themselves from their blogging selves during the interviews: "the blog is not me"; the blog and the off-blog settings are "two different worlds". As specified in Sara's quote opening this section, the self-presentation focused on fashion and beauty is justified by its appeal to female audiences and an expression of only one of her interests. Hiding personal or negative emotions is in turn framed as protecting privacy and not making oneself vulnerable. As Ella put it: " The most private I get (in the blog) is about my dog”. At the same time, the girls realize that they can be judged as "superficial", "stupid" or "pink bloggers" because of their selective and polished performances. Distancing oneself from one's blogging self seems to be a way to deal with the unease of being perceived as a "superficial" girl - an image that clashes with the demands of being the modern girl who is supposed to have it all: good looks with brains and an interesting social life (Nielsen 2014). 


\section{Fit-in-and-be-myself strategy}

The typical elements of the fit-in-and-be-myself strategy are: combining life accounts and style with opinionated or emotional content; attempts to present both the positive and negative aspects of one's life; a moderate degree of identification with the blogging self. Karoline distances herself from the "pink-blogger" label right at the start of our first interview:

I would say that I have an ordinary blog. This is not a pink blog. Because I don't present everything as pink and perfect but I try to balance the types of posts I publish... I make sure not to publish posts that are too personal, but I also make sure that I look normal. That I also have bad days and not a perfect life like in the pink blogs. Karoline, interview.

Karoline wants to make sure she does not look "perfect" like "pink bloggers". This is typical for the fit-in-and-be-myself strategy. On the one hand, there is the attempt to perform a blogging self that complies with the community norms that dictate staging a positive, fashionable and polished blogging self. On the other hand, there is the desire to stay "normal" and not perceived as "fake" or "superficial".

Posting about own views and sharing personal or difficult experiences is one way this struggle for "looking normal" is mirrored in the blogs. While Sofie posted many outfit photos and inspirational collages depicting magazine-cover-looking girls, she also used her blog to "get things off her chest", writing about bullying or eating disorders. She also shared her own difficult experiences with individual readers through email correspondences, something she framed as supportive for them. Pia published some posts out of keeping with a positive façade: how she "hates everything about her body" or struggles with an injury. However, publishing posts about "social dilemmas" is viewed as challenging because this demands a readiness to stand up for one's convictions, including offline, perhaps in front of schoolmates who might confront the blogger about her views. While avoiding controversy is even stronger in the adjustment strategy, where all opinionated content is excluded, here publishing such content is desirable, though often accompanied with the fear of being criticized. Posting about negative life experiences is framed as challenging because this means disclosure and vulnerability.

Also the photos are less staged and polished, evoking more documentations of everyday life than fashion shoots. Karoline frames looking as good as possible in the photos as something "everybody wants", but associates this with being a "pink blogger", someone she "tries hard" not to be. This illustrates the challenge this strategy entails: striking a balance where one fits in to the community's norms of perfectibility (McRobbie 2000 cited in Jackson 2016) but also remains "normal" enough to avoid being labelled as a superficial "pink blogger". Because this strategy involves a higher degree of identification with one's blogging self, the pressure is greater than in case of the adjustment strategy.

\section{Contestation strategy}

This strategy undermines the normative expressions of femininity in mainstream blogging. Elements typical for this strategy are: publishing a lot of opinionated and emotional content; presenting own life and body in realistic or subversive ways; and a high degree of identification with one's blogging self. Marie's blog post illustrates the contestation strategy: 
I am not after fame and popularity based on what I look like. I am not really after popularity, so that everyone in Norway knows who I am, but I want to get through to people. ... I want people to understand what the world is like, that not everyone is doing fine. I want to put this into focus because my friends and I have gone through different things! Marie, blog post.

Marie refuses to use her looks to gain popularity but wants to articulate teenagers' experiences. Janne's agenda is to create an alternative to the "manipulated and perfect images of what girls look, behave, and live like" constructed in the most popular blogs. In this strategy, socially engaged topics are framed as most appealing. Opinion posts abound and cover topics like beauty tyranny, peer pressure, depression, bullying, feminism, politics, suicide or relationships. This is different compared with the fit-in-and-be-myself strategy, where expressing opinions is desirable but only partially realized due to the fear of critical comments. The posts are usually quite long and sometimes elicit discussions between the commenting readers, which seldom occurs in the other strategies. These comments tend to relate to the content of the blog rather than the blogger' appearance. Much interaction also takes place through private correspondences, where the blogging self is performed off the blog.

This strategy presents the body in realistic or subversively non-normative ways. Janne performed an ironic, "imperfect" blogging self by posting almost exclusively unflattering photos of herself with messy hair, exposed spots, and unfashionable clothes that caricature the outfit photos. Her blogging self emphasizes her flaws in order to rebel against polished mainstream self-presentations, unlike the other strategies that minimize flaws. Nadira published several outfit photos: her agenda was to inspire "those who may not feel that their body fits in". She described herself as "not the catwalk type", not fitting in to the current ideal of a slim, toned body. By continuing to publish outfit photos in spite of the judging audience's disciplining comments about her weight or unshaved armpits, she contested the narrow ideals of femininity that privilege slimness.

The experienced identification with one's blogging self is distinct in the contestation strategy compared with the others. Janne even said that the blog "was her identity" for some time.

\section{Blogging selves across time and contexts}

While most girls at the beginning of their participation in the study followed the fit-inand-be-myself strategy, none of them did so towards the end: they either quit blogging or switched to another strategy.

Karoline and Emma switched to the adjustment strategy. Over time, their blogs included outfit photos more frequently, and fewer opinion posts. During our second interview, Karoline gladly said she now had a bigger audience and received sponsored products. Emma deleted the blog's sub-page related to her engagement in a political party because she was "no longer so active in the party" and "politics was not really interesting to the readers" in contrast to "girl stuff". Over time, their blogging selves emphasized style more than "social dilemmas" because of the audience's positive responses. This supports Lomborg's (2012) findings that the blogger-readers interaction "has a conservative effect on the blog content", leading to a stabilization of topics over time (427) and thus reinforcing the emphasis on a few selected aspects of the blogging self that are most appealing to the audience. 
Moreover, Emma made a link between audience-appealing content and sponsorship. In order to maintain sponsorship cooperation, where the blogger receives products in exchange for advertising them in her blog, she needs to maintain a certain audience size specified by the sponsoring company. In this case, maintaining commercial cooperation seems to be an incentive for adjusting the blogging self to the audience's preferences. Only some of the participants actively looked for sponsorship. Still, most of them, regardless of strategy, framed sponsorship cooperation as desirable as long as bloggers are "honest" about the advertised products. This seems to indicate an increasing normalization of the commercialization of personal blogs.

Marie switched from the fit-in-and-be-myself strategy to the contestation strategy. When I interviewed her the first time, she said she was "a bit like a pink blogger". Her initial goal was to "get the kind of attention Andrea Badendyck and Emilie Nereng have". These popular bloggers had the right looks, the right clothes, many readers, and material benefits, which symbolized status among Marie's schoolmates. By emphasizing looks and outfits in her blogging self, she wanted to prove she was "as good as" them, gaining status on their terms by becoming a popular blogger. This documents that the offline interactions with her schoolmates influenced Marie's blogging self. In retrospect, however, she framed this self-presentation as "not her". During the second interview, she no longer identified herself as a "pink blogger".

Janne quit blogging although she strongly identified with her blogging self performed in the contestation strategy. As she told me during our second interview, she began to wear make-up and was no longer comfortable with publishing ugly photos of herself. She felt pressured to live up to - or as she said, "live down to" - her flawed, self-ironic blogging self. She was afraid to "lose face", say, by publishing photos of her wearing make-up: a pretty, made-up blogging self seemed incompatible with her agenda. This does not mean that she considered being pretty and opinionated as mutually exclusive. Rather, she felt that acting prettily clashed with her subversive blogging self, which was selective and performed for the sake of the blogging context.

Interestingly, Janne seemed to perform her blogging self offline when giving interviews to the media or meeting with one of her readers in person. "I didn't know how cool she thinks I am", she said, recalling her nervousness before meeting a reader, as if she wanted to be the person the reader knew from the blog. Ella, who used the adjustment strategy, also seemed to perform her blogging self in offline settings, like attending the blog awards ceremony or being interviewed about fashion tips in one of Norway's biggest newspapers. Referring to this interview, she said: "maybe not me, but (the name of her blog persona) certainly has a voice" that people want to listen to. This appears to indicate that the girls also kept in character in offline settings during interactions that revolved around their blogging activities.

\section{Concluding discussion}

On the basis of the empirical analyses of the interviews with teenage girls and their blogs, I have identified that the girls performed blogging selves reflexively and strategically but they were held accountable according to the gendered norms and discourses manifested both within the online-based blogging community and beyond - in the offline settings. The blogging selves changed over time and the girls identified with them to different degrees. 
On the one hand, the online-based interactions with the girls who read the blogs shape the blogging selves. This judging audience (Hirdman 2007) evaluates the bloggers according to the norms of the postfeminist perfectibility (McRobbie 2000) and of respectability (Ambjörnsson 2004). On the other hand, the offline-based interactions with their schoolmates and the trivializing label of "pink blogger" also frame the girls" performances. Public engagement based on life accounts and the stereotypically feminine area of style seems incompatible with the normative ideal of a gender-equal Nordic Girl granted with endless possibilities (Formark \& Bränström Öhman 2013). Whereas some have argued that girls are freer to experiment with femininity in online settings compared with the offline settings, this investigation concludes that the girls' performances of self are complex balancing acts disciplined according to the normative ideals of the postfeminist body and the ideals of Nordic Girlhood.

Still, while most previous studies emphasize the importance of striking a balance between sexually available and respectable femininity, in this investigation the dimensions of the looks and the brains came across as essential. The dimension of the looks relates, of course, to sexuality: the girls wanted to display attractive bodies that match the current ideals of feminine beauty. Still, those who enhanced their photos talked about the right body shape (slim but toned) and fashionable outfits and avoided posting photos that could be viewed as sexualized. Or, maybe they did not want to say they wanted to look sexy when talking to me? After all, research interviews were also social interactions, where we performed particular selves to create the desired impressions (Goffman 1959). I have not registered using fashion and style in the spirit of third-wave feminism as "a recognition of femininity as a constructive force to be used against patriarchy 'from within"' (Sundén \& Sveningsson Elm 2007: 8). Instead, in the adjustment strategy, the girls distanced themselves from blogging selves that emphasized the looks and style because they clashed with their self-perception as being smart and opinionated off the blog, even though they felt they were being misjudged. The fit-in-and-be-myself strategy involved the attempts to combine "girl stuff" with "social dilemmas" the girls felt they "should" blog about in just the right proportions. In turn, the contestation strategy that emphasized the brains was accompanied by the feeling of acting "unwomanly" (Sveningsson Elm 2009) owing to the incompliance with the normative body ideals.

It is possible that the looks and the brains dimensions were important because of the social positioning of mainstream female bloggers in Norway as superficial "pink bloggers". The girls might have responded to this label by insisting that they were not superficial, but have opinions and are "interested in what's going on in the world". However, the looks and the brains dimensions might also be indications of requirements towards contemporary Norwegian girls formulated by Nielsen (2014): both pretty and smart. The girls experienced self-presentations dominating in mainstream blogging as polished and body-focused, but they responded to them differently: trying either to comply with or to subvert them. The more polished, easily consumable (Marwick \& boyd 2011) and body-focused blogging selves they performed, the less they identified with them.

Finally, whereas earlier studies propose that young people tend to create identity online consistent with identity offline (Huffaker \& Calvert 2005, Davis 2010), my results also indicate a reversal. Some participants seemed to perform their blogging selves not only in the online settings, but also offline, during face-to-face interactions with their readers and people who got to know them as bloggers. This expands Lomborg's (2012) 
concept of the blogging self in that this self can be accomplished not only online but also offline. In broader terms, this finding contributes to the theorization of performing identity as self by documenting not only that people take performances of self originating in the offline-based contexts to the online-based contexts, but also that they can keep in their online-based characters during offline-based interactions.

\section{Notes}

1. These photos present the blogger in various outfits and sometimes include information about the place of purchase (Palmgren 2010).

2. I acknowledge the class dimensions in Nielsen's (2014) analysis but I do not address them in this article.

3. I define top female bloggers as those listed at top positions of the Norwegian blogging rankings over a longer time, with stable audiences counting up to tens of thousands of readers per day.

4. The first four participants were interviewed for the second time about one year after interview 1 .

5. One participant was interviewed by the phone.

6. The analyses included the first ten blog posts with accompanying comments published in three selected months: six months prior to interview 1 , the month of interview 1 , and the month of interview 2 . The collection of blog samples did not coincide for all participants but covered a similar time span of about 12 months.

7. Approximate audience sizes ranged from 20 to 5000 unique readers per day. These are unstable, changing on a daily basis.

\section{References}

Abidin, Crystal \& Thompson, Eric (2012). Buymylife. com: Cyber-femininities and Commercial Intimacy in Blogshops. Women's Studies International Forum, 35: 467-77.

Altheide, David L. (1996). Qualitative Media Analysis. Thousand Oaks: Sage Publications.

Ambjörnsson, Fannny (2004). I en klass för sig: genus, klass och sexualitet bland gymnasietjejer. PhD dissertation. Stockholm University.

boyd, danah (2008). Why youth (heart) Social Network Sites: The Role of Networked Publics in Teenage Social Life, pp. 119-142 in Buckingham, David (ed.) Youth, Identity, and Digital Media. Cambridge: The MIT Press.

Butler, Judith (1990). Gender trouble: Feminism and the subversion of identity. New York: Routledge

Daneback, Kristian (2006). Love and sexuality on the internet. Department of Social Work, Göteborg University

Davis, Katie (2010). Coming of Age Online: The Developmental Underpinnings of Girls' Blogs. Journal of Adolescent Research, 25(1): 145-171.

Dmitrow-Devold, Karolina (2017). What Matters to the Girls? Norwegian Girls' Experiences of Digital Competences in Mainstream Blogging. Young - Nordic Journal of Youth Research, 25(2): 1-18.

Dmitrow-Devold, Karolina (2013). ‘Superficial! Body Obsessed! Commercial!' Norwegian Press Representations of Girl Bloggers. Girlhood Studies, 6(2): 65-82.

Dobson, Amy Shields (2012). 'Individuality is Everything': ‘Autonomous’ Femininity in MySpace Mottos and Self-descriptions. Continuum, 26(3): 371-83.

Duguay, Stefanie (2016). 'He Has a Way Gayer Facebook than I Do’: Investigating Sexual Identity Disclosure and Context Collapse on a Social Networking Site. New media \& Society, 18: 891-907.

Fenstermaker, Sarah \& West, Candace (2002). Doing Gender, Doing Difference: Inequality, Power, and Institutional Change. New York: Routledge.

Formark, Bodil \& Bränström Öhman, Annelie (2013). Situating Nordic Girls' Studies. Girlhood Studies, 6(2): 3-10.

Fuglerud, Magni O. (2013). Ung, Digital og Listet - Hvordan Rosabloggen Tok Over Samfunnet, pp. 209-230 in Bjørkelo, Kristian A. (ed.) Gi Meg en Scene! Norsk blogghistorie - Ti Ar med Terror, Traumer og Dagens Outfit. Oslo: Humanist Forlag.

Gill, Rosalind (2007). Postfeminist Media Culture. Elements of a Sensibility. European Journal of Cultural Studies, 10(2): 147-66.

Goffman, Erving (1959). The Presentation of Self in Everyday Life. Garden City: Doubleday.

Goffman, Erving (1976). Gender Display. Studies in the Anthropology of Visual Communication, 3(2): 69-77.

Gram, Mette \& Richardt, Laura (2006). 'All Eyez On Me' - Unge Pigers Seksualiserede Iscenesaettelser på Arto. Social Kritik, 105: 71-82. 
Gray, Ann (1992). Video Playtime: The Gendering of a Leisure Technology. London: Routledge.

Helseth, Hannah (2010). Generasjon sex. Oslo: Manifest

Herring, Susan C.; Inna Kouper, Lois; Scheidt, Ann \& Wright, Elijah L. (2004). Women and Children Last: The Discursive Construction of Weblogs. Paper read at Into the Blogosphere: Rhetoric, Community, and Culture of Weblogs.

Hirdman, Anja (2007). Visuellt Genus - Internet, Självbilder och Mediala Representationer. pp. 255-327 in Löfgren-Mårtenson, Lotta; Månsson, Sven-Axel \& Knudsen, Susanne (eds.) Unge, Køn og Pornografi i Norden-Mediestudier. Copenhagen: NIKK

Huffaker, David A. \& Calvert, Sandra L. (2005). Gender, Identity, and Language Use in Teenage Blogs. Journal of Computer-Mediated Communication, 10(2).

Jackson, Sue (2016). They've Always Got Flat Tummies and It Really Bugs Us, pp. 69-83 in Coffey, Julia; Budgeon, Shelley \& Cahill, Helen (eds.) Learning Bodies. The Body in Youth and Childhood Studies. Singapore: Springer.

Jávo, Iiná Márjá (2012). Psychosocial Predictors of an Interest in Cosmetic Surgery: Based on a Population Study of Young Norwegian Women. PhD dissertation. University of Tromsø.

Kapidzic, Sanja \& Herring, Susan (2014). Race, Gender and Self-presentation in Teen Profile Photographs. New Media \& Society, 17(4): 958-976.

Kelly, Deirdre M, Pomerantz, Shauna, \& Currie, Dawn H (2006). 'No Boundaries'? Girls' Interactive, Online Learning About Femininities. Youth \& Society, 38(1): 3-28.

Knudsen, Susanne (2007). Betydning og Brug av Internettet. Om Gratis Pornografi og Selvpraesentationer på Internettet i Norge, pp. 159-254 in Löfgren-Mårtenson, Lotta; Månsson, Sven-Axel \& Knudsen, Susanne (eds.) Unge, Køn og Pornografi i Norden - Mediestudier. Copenhagen: NIKK

Lincoln, Yvonna S. \& Egon G. Guba (1985). Naturalistic Inquiry. Beverly Hills: Sage.

Lomborg, Stine (2012). Negotiating Privacy Through Phatic Communication. A Case Study of the Blogging Self. Philosophy \& Technology, 25(3): 415-34.

Lövheim, Mia (2011). Personal and Popular. The Case of Young Swedish Female Top-bloggers. Nordicom Review, 32(1): 3-16.

Marwick, Alice (2014). Gender, Sexuality, and Social Media, pp. 59-75 in Hunsinger, Jeremy \& Senft, Theresa (eds.) The Social Media Handbook. New York: Routledge.

Marwick, Alice \& boyd, Danah (2011). To See and Be Seen: Celebrity Practice on Twitter. Convergence: the International Journal of Research into New Media Technologies, 17 (2):139-58.

McRobbie, Angela (2000). Feminism and Youth Culture: from 'Jackie' to 'Just Seventeen'. London: Macmillan.

McRobbie, Angela (2009). The Aftermath of Feminism: Gender, Culture and Social Change. Los Angeles: Sage.

Moje, Elizabeth Birr \& Allan, Luke (2009). Literacy and Identity: Examining the Metaphors in History and Contemporary Research. Reading Research Quarterly, 44(4): 415-437.

Nakamura, Lisa (2002). Cybertypes, Race, Ethnicity, and Identity on the Internet. New York: Routledge.

Nielsen, Harriet Bjerrum (2014). Forskjeller i Klassen: Nye Perspektiver på Kjønn, Klasse og Etnisitet $i$ Skolen. Oslo: Universitetsforlaget.

Norwegian Media Authority (2016). Barn og Medier 2016 - Fakta om Barn og Unges (9-16 år) Bruk og Opplevelser av Medier.

Palmgren, Ann-Charlotte (2010). Posing My Identity. Today's Outfit in Swedish Blogs. Observatorio (OBS*), $4(2)$.

Rettberg, Jill W. (2014). Seeing Ourselves through Technology: How We Use Selfies, Blogs and Wearable Devices to See and Shape Ourselves. Basingstoke: Palgrave Macmillan.

Robinson, Laura (2007). The Cyberself: the Self-ing Project Goes Online, Symbolic Interaction in the Digital Age. New Media \& Society, 9(1): 93-110.

Rysst, Mari (2010). 'Healthism' and Looking Good: Body Ideals and Body Practices in Norway. Scandinavian Journal of Public Health, 38(5): 71-80.

Rysst, Mari \& Roos, Gun (2014). Retusjert Reklame og Kroppspress. Oslo: SIFO.

Schor, Juliet (2004). Born to Buy: The Commercialized Child and the New Consumer Culture. New York: Scribner.

Silverman, David (2006). Interpreting Qualitative Data: Methods for Analysing Talk, Text and Interaction $\left(2^{\text {nd }}\right.$ ed.). London: Sage.

Stern, Susannah R. (2004). Expressions of Identity Online: Prominent Features and Gender Differences in Adolescents' World Wide Web Home Pages. Journal of Broadcasting \& Electronic Media, 48(2): 218-243.

Sundén, Jenny \& Sveningsson Elm, Malin (2007). Cyberfeminism in Northern Lights. Introduction, pp. 1-29 in Sveningsson Elm, Malin \& Sundén, Jenny (eds.) Cyberfeminism in Northern Lights. Gender and Digital Media in a Nordic Context. Cambridge: Cambridge Scholars Publishing. 


\section{Karolina Dmitrow-Devold}

Sümer, Sevil; Halsaa, Beatrice \& Roseneil, Sasha (2014). Gendered Citizenship in a Multidimensional Perspective: the Challenges Facing Norway within the Nordic Model. Nordic Journal of Feminist and Gender Research, 22(4): 283-298.

Sveningsson Elm, Malin (2007). Doing and Undoing Gender in a Swedish Internet Community, pp. 104-129 in Sveningsson Elm, Malin \& Sundén, Jenny (eds.) Cyberfeminism in Northern lights. Gender and digital media in a Nordic context. Cambridge: Cambridge Scholars Publishing

Sveningsson Elm, Malin (2009). Teenagers Get Undressed on the Internet. Nordicom Review, 30(2): 87-103.

Thurlow, Crispin; Lengel, Laura, \& Tomic, Alice (2004). Computer Mediated Communication. London: SAGE Publications.

Turkle, Sherry (1995). Life on the Screen. Identity in the Age of Internet. New York: Simon and Schuster. West, Candace \& Zimmerman, Don H. (1987). Doing Gender. Gender \& Society, 1(2): 125-51.

West, Candace \& Fenstermaker, Sarah (1995). Doing Difference. Gender \& Society, 9(1): 8-37.

Willem, Cilia et al. (2012). Girls on Fotolog: Reproduction of Gender Stereotypes or Identity Play? Interactions: Studies in Communication \& Culture, 2(3): 225-242.

KAROLINA DMITROW-DEVOLD, PhD candidate, Research Centre for Child and Youth Competence Development, Inland Norway University of Applied Sciences, karolina.dmitrow-devold@inn.no 